\title{
КОНЦЕПТУАЛЬНАЯ МОДЕЛЬ ЕДИНОГО ИНТЕРНАЦИОНАЛЬНОГО ОБРАЗОВАТЕЛЬНОГО ПРОСТРАНСТВА КАК ФАКТОР УВЕЛИЧЕНИЯ ЭКСПОРТА УСЛУГ ВЫСШЕГО ОБРАЗОВАНИЯ В РОССИЙСКОЙ ФЕДЕРАЦИИ
}

Сегодня в условиях усиления внимания к таким трендам развития современной экономики, как конкурентоспособность, инновации, производительность труда, экономика знаний и цифровая экономика, университеть начинают рассиатриваться как драйверы развития территорий, а интернационализация высиего образования - как показатель конкурентоспособности национальной системы образования. Это также обосновано ростом количества межсународных студентов и, как следствие, объемов мирового рынка образовательных услуг. Таким образом, в ближайшей перспективе для построения эффективной политики в сфере экспорта образовательных услуг в рамках основных тенденций и императивов, определяюиих выбор межсународными студентами страны обучения, необходимо на основании анализа фактолого-эмпирических данных построчть концептуальную модель единого интернационального образовательного пространства.

Ключевые слова: единое интернациональное образовательное пространство, интернационализация, экспорт услуг высшего образования, мировая экономика.

\section{Elena Zashchitina}

CONCEPTUAL MODEL OF INTEGRATED INTERNATIONAL EDUCATIONAL ENVIRONMENT AS A FACTOR OF INCREASE

IN EXPORT OF HIGHER EDUCATION SERVICES IN RUSSIAN FEDERATION

Today, universities are beginning to be considered as drivers of the development of territories, and the internationalization of higher education as an indicator of the competitiveness of the national education system. It is happening in the context of increasing attention to such trends in the development of the modern economy as competitiveness, innovation, productivity, knowledge economy and digital economy. This is also justified by the increase in the number of international students and, as a consequence, the volume of the world market of educational services. Thus, in the short term, it is necessary to build a conceptual model of integrated international educational environment on the basis of the analysis of factual and empirical data. It could be useful in building an effective policy in the field of export of educational services, within the main trends and imperatives that determine the choice of international students of the country of study.

Key words: integrated international educational environment, internalization, export of higher education services, international economy.

Bведение /Introduction. В современном быстроизменяющемся мире люди не только являются создателями товаров, производителями работ и услуг и носителями спроса, но и становятся ядром качественных изменений и преобразований в экономике знаний и современной цифровой экономике. Также ускорение происходящих процессов глобализации и интернационализации и переход общества на новый постиндустриальный уровень приводит к тому, что образовательная услуга начинает рассматривается как один из факторов конкурентоспособности государства в целом и отдельных его субъектов в частности.

Государственная политика в сфере экспорта образования реализуется для повышения качества образования и конкурентоспособности системы образования (в том числе образовательной системы) и направлена на разработку и реализацию эффективной стратегии экспорта образова- 
ния, включающей в себя мероприятия, охватывающие все уровни системы образования и все программы обучения, с учетом возможных стратегий интернационализации, среди которых выделяются: внутренняя интернационализация, совместные образовательные программы и программы двойных дипломов, открытие филиалов за рубежом и работа в рамках сетевых университетов, развитие онлайн-обучения, развитие мобильности студентов и сотрудников.

При этом для получения конкурентных преимуществ, способствующих выходу страны в ТОП-лидеры по уровню интернационализации и занимаемым объемам международного рынка образования, а также достижению целевых показателей, поставленных в приоритетных государственных программах, на государственном уровне необходимо внедрение сразу нескольких форм интернационализации и использование соответствующих инструментов и механизмов на макроуровне - со стороны государства - и на микроуровне - со стороны высшего учебного заведения. Зарубежный и российский опыт показывает, что в подобной ситуации наиболее эффективным будет организация интеграционных процессов в рамках сетевых структур, которые позволяют повысить адаптивность к изменяющимся условиям рыночной коньюнктуры, более полно раскрыть имеющийся потенциал участников сети, снизить издержки за счет создания их более рациональной структуры, исключения дублирования при совместном выполнении проектов, создать эффективный механизм обмена информацией и тиражирования наиболее успешного опыта.

Таким образом, предметом настоящей статьи является анализ механизмов создания концептуальной модели единого интернационального образовательного пространства, способствующей увеличению экспорта услуг высшего образования в Российской Федерации.

Maтериалы и методы / Materials and methods. При анализе имеющегося опыта в рамках функционирования сетевых структур в образовательном пространстве использовались методы компаративного анализа, сравнений и аналогий. При формулировании базовых понятий, среди которых «сетевая структура» и «сетевой университет», а также при разработке концептуальной модели единого интернационального образовательного пространства использовались методы системного анализа и синтеза, классификации, количественного и качественного анализа. Также при структурировании информации использовались методы графической интерпретации и табличного представления

Результаты и обсуждение/Results and discussion. В настоящее время интернационализация высшего образования становится показателем конкурентоспособности национальной системы образования в условиях борьбы за таланты, позволяя странам развивать собственные системы образования не только на национальном, но и на международном уровнях.

По всем рассмотренным формам интернационализации в настоящее время Российская Федерация при наличии неоспоримых сильных сторон и возможностей сталкивается с большим количеством угроз и слабых сторон. В основном это происходит потому, что на настоящий момент существует разрыв между теорией, мировым опытом и практикой интернационализации российского образования, превалирующий инструментализм приводит к нескоординированным и фрагментарным инициативам, а сама интернационализация является не инструментом взаимодействия государств, а процессом взаимодействия культур и интегрирования глобального и локального контекстов в отдельном высшем учебном заведении [1].

Данный анализ позволил сделать вывод, что наиболее эффективным подходом, позволяющим достичь наилучших значений в аспекте интернационализации высшего образования, является глонакальный подход, на основании принципов которого возможно представить схему действия акторов, участвующих в процессах интернационализации высшего образования [2] (рис.1).

Принципы глонакольного подхода, позволяющие осуществлять интернационализацию за счет преломления внешних и внутренних факторов и воздействия через призму глобальных, национальных и локальных возможностей и интересов акторов, а также опыт стран - ведущих экс- 
портеров высшего образования, основанный на том, что для повышения экспорта образовательных услуг на глобальном уровне в первую очередь необходимо продвижение бренда образования, включающего в себя создание интегрированной системы привлечения международных студентов, позволили сделать вывод, что наиболее эффективным при интернационализации будет использование адаптированных сетевых структур, объединяющих два или более учреждения высшего образования, преследующих общие цели и занимающихся решением общих долгосрочных проблем на основе совместного использования финансовых, материально-технических, интеллектуальных и иных ресурсов, оставаясь при этом независимыми хозяйствующими субъектами [3].

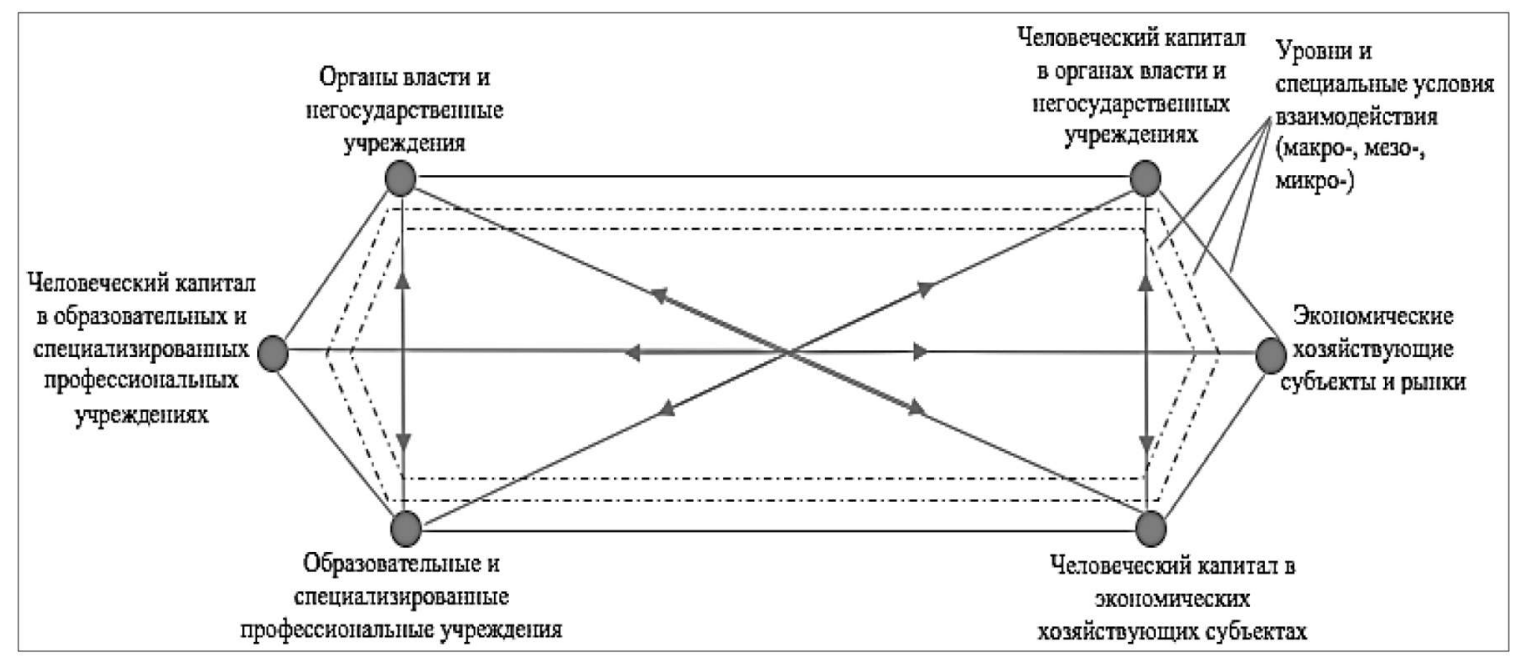

Рис. 1. Схема действия акторов, участвующих в процессах интернационализации высшего образования: глонакальный подход

В данном контексте сеть должна строиться на основании определенных принципов с учетом предлагаемых классификаций (рис. 2) с помощью [4]:

- специализированного способа взаимодействия (взаимодействие по вертикали и горизонтали организаций, зависимых друг от друга в экономическом отношении, но при этом являющихся самостоятельными в правовом отношении);

- специализированного способа интеграции организаций (объединение организаций, координация их деятельности и привлечение новых партнеров через систему горизонтальных и вертикальных кооперационных соглашений и контрактов);

- $\quad$ сопоставления с отдельным институтом, действующим по принципу взаимодействия и интеграции организаций, имеющих близкую систему ценностей.

Таким образом, в преломлении к рынку образовательных услуг сетевой является та структура, которая объединяет два или более учреждения высшего образования, преследующих общие цели и занимающихся решением общих долгосрочных проблем на основе совместного использования финансовых, материально-технических, интеллектуальных и иных ресурсов, оставаясь при этом независимыми хозяйствующими субъектами [5].

В сфере высшего образования наиболее эффективной разновидностью крупных сетей, охватывающих широкий спектр социально-экономических аспектов, становятся образовательные кластеры (рис. 3).

В данном контексте опыт функционирования образовательных кластеров во всем мире показывает, что они позволяют выделить за счет объединения ресурсов, общего маркетинга и единого позиционирования на рынке на мировой арене вузы, имеющие главенствующую роль в 
кластере. Их эффективность определяется через оценку роли конкретных вузов в общем объеме оказанных услуг высшего образования $[6,7]$. Таким образом, на основании анализа опыта зарубежных и отечественных ученых (в т. ч. М. Портера и М. Войнаренко) применительно к образовательному кластеру может быть сформулировано следующее определение: образовательный кластер представляет собой форму сетевой организации учреждений высшего образования, позволяющую адаптировать их внутреннюю структуру и внешние взаимосвязи к быстроизменяющейся внешней среде за счет создания эффективной кооперации, оптимизации усилий и ресурсов, повышения гибкости и мобильности вузов, создания системы управления знаниями, а также выстраивания диалога между другими образовательными организациями (различных ступеней образования), органами государственной власти, коммерческими и некоммерческими организациями, научными структурами, позволяющего развивать конкурентные преимущества как внутри страны, так и за ее пределами $[8,9]$.

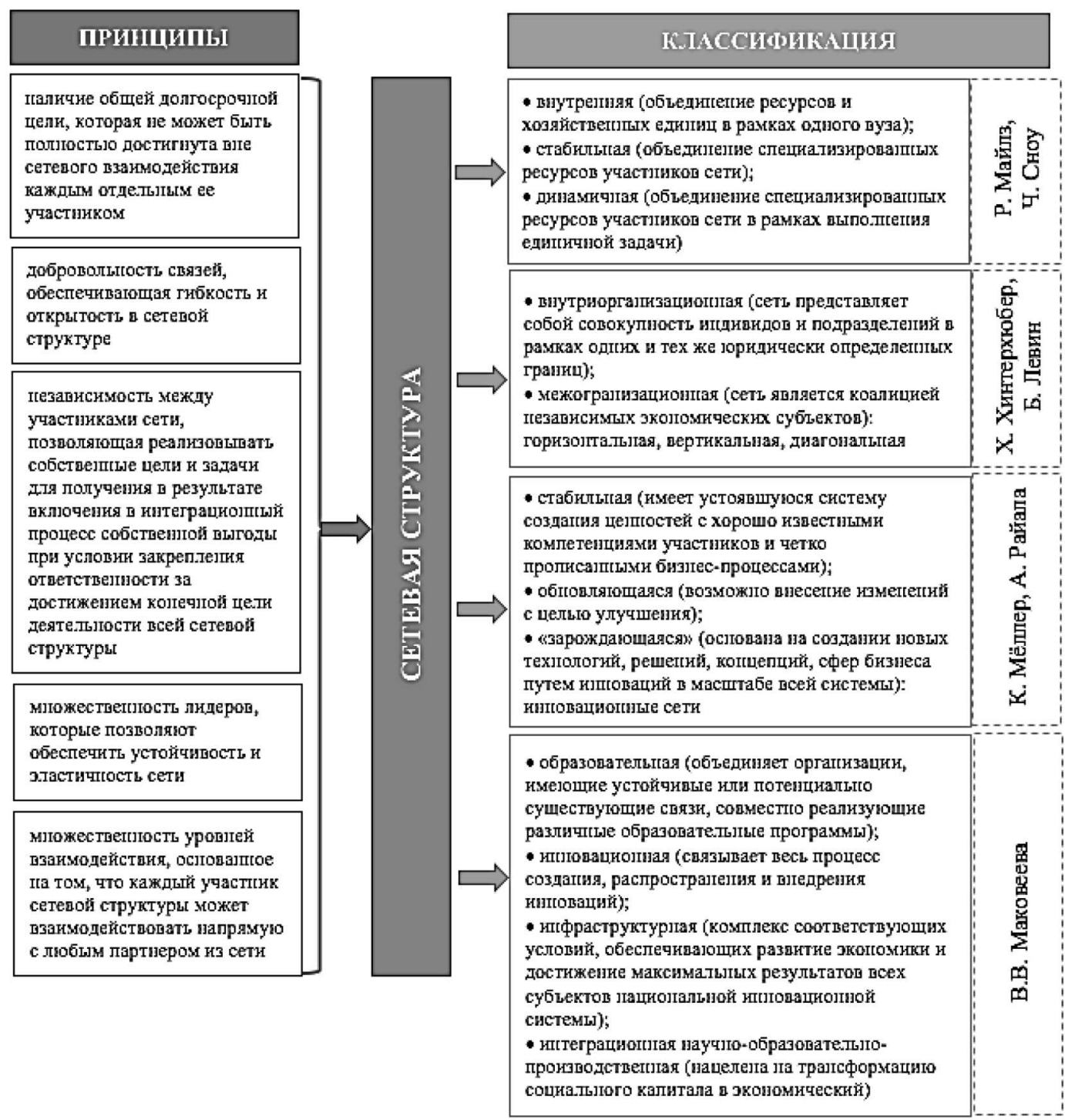

Рис. 2. Сетевая структура взаимодействия участников образовательного кластера: принципы построения и классификация 


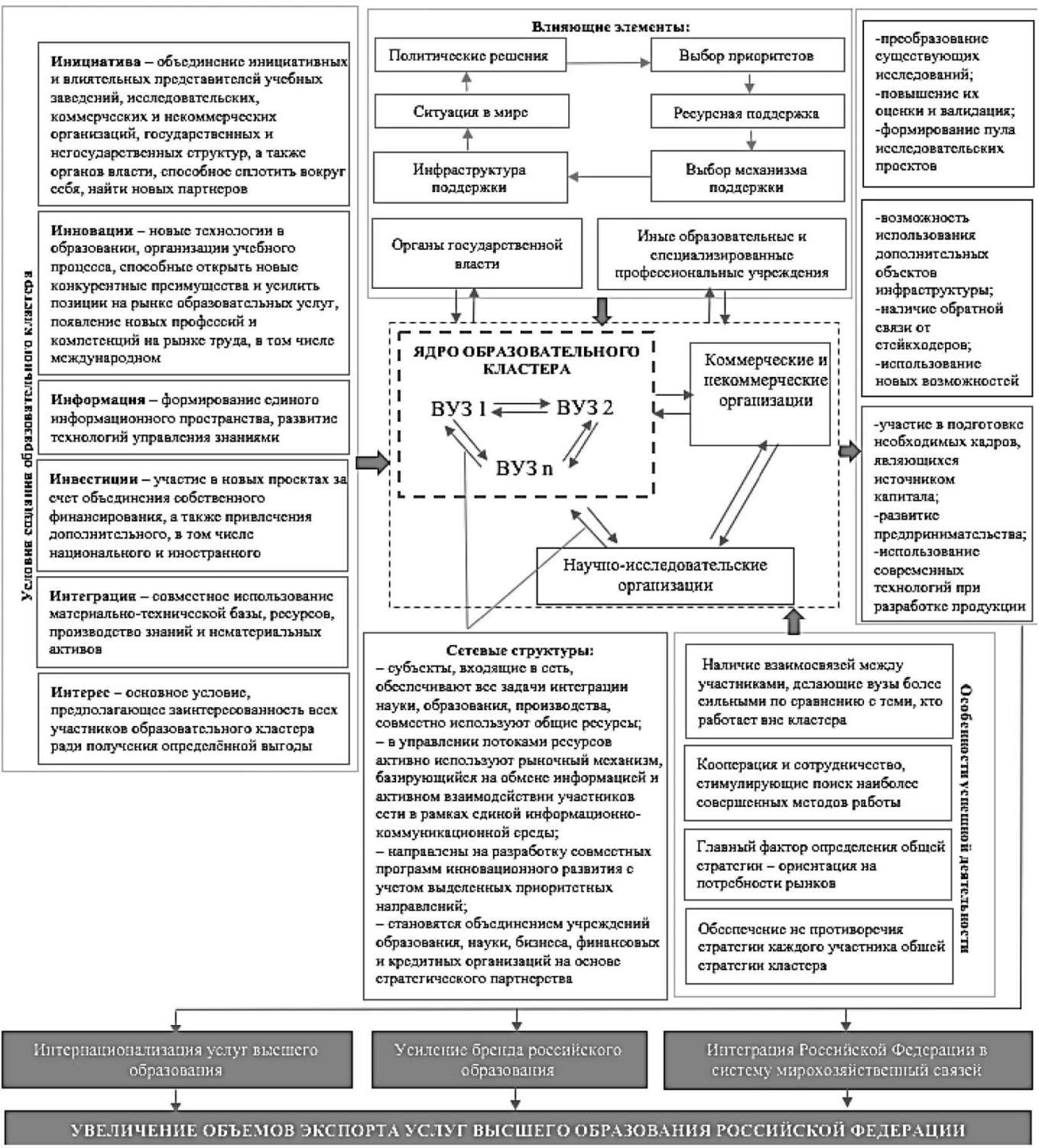

Рис. 3. Схема формирования образовательного кластера федерального значения и его влияния на интернационализацию

Единое интернациональное образовательное пространство в Российской Федерации в первую очередь предполагает развитие бренда российского образования и рост его привлекательности за счет совместных скоординированных действий всех структур, прямо или опосредованно связанных с повышением конкурентоспособности российского образования. В связи с этим единое интернациональное образовательное пространство предлагается сформировать из образовательных кластеров, созданных в каждом федеральном округе.

Данная модель позволит более пропорционально распределить международных студентов по территории Российской Федерации, в том числе при помощи учета одного из важных факторов выбора международными студентами страны обучения, а именно географической отдаленности, и наиболее эффективно проявить черты и признаки, присущие конкурентоспособному образовательному кластеру (см. табл.) [10]. 
Черты и принципы конкурентоспособного образовательного кластера

\begin{tabular}{|c|c|}
\hline Черты & Признаки \\
\hline $\begin{array}{l}\text { • главный фактор развития - возрастающая отдача } \\
\text { от накопления знаний за счет роста инвестиций в } \\
\text { человеческий капитал и новые технологии; } \\
\text { • ограниченное число участников для синергети- } \\
\text { ческого эффекта от их совместного участия и } \\
\text { вложения ресурсов; } \\
\text { - главный приоритет для кластеризации - крити- } \\
\text { ческая масса высококвалифициро-ванных чело- } \\
\text { веческих ресурсов }\end{array}$ & $\begin{array}{l}\text { - устойчивая позиция на российском и мировом } \\
\text { рынках образовательных услуг; } \\
\text { - технологическое превосходство и способность к } \\
\text { продуцированию инноваций; } \\
\text { - способность всех участников к самообучению }\end{array}$ \\
\hline
\end{tabular}

При этом каждый отдельный образовательный кластер федерального значения должен включать в себя проекты, направленные на образовательную деятельность, проектно-экспериментальную деятельность, профориентацию и планирование карьеры за счет информационного, организационно-методического и кадрового механизмов, позволяющих выбирать учебные заведения, в том числе на основе индивидуальных карьерных карт - траектории развития профессиональной деятельности.

Данная модель позволит помимо формирования бренда образования и привлечения международных студентов решать следующие задачи: совершенствование нормативных, организационных и информационных механизмов формирования и осуществления профориентационной работы; создание комплексной системы профессиональной ориентации на основе межведомственного взаимодействия; обеспечение потребности предприятий, осуществляющих деятельность на территории округа, в необходимых кадрах; подготовка и профессиональное развитие кадрового ресурса для предприятий округа; реализация профориентационной работы на основе социально-экономической информации о перспективах развития экономики округа.

Также для эффективного функционирования образовательного кластера необходимо объединение усилий министерств и ведомств как непосредственно курирующих образовательную деятельность (Министерства науки и высшего образования и Министерства просвещения), так и «сопутствующих».

Таким образом, можно представить модель единого интернационального образовательного пространства, включающего в себя образовательные кластеры федерального значения (рис. 4).

Эффективность данной модели можно оценивать через эффективность каждого образовательного кластера по трем критериям: позиция на рынке, создание конкурентных преимуществ, способность к развитию, - которые включают в себя определенные показатели и способы измерения (рис. 5).

Для создания и эффективного функционирования образовательный кластер должен обладать определенными минимальными требованиями, среди которых: количество вузов (не менее 5), количество научно-исследовательских организаций (не менее 1 в каждом регионе, где расположен вуз-участник), количество предприятий (не менее 3 в каждом регионе, где расположен вуз-участник), наличие связей между членами кластера и другими государственными и негосударственными учреждениями, а также региональными органами власти, готовность региона принимать международных студентов (уровень развития региональной системы высшего образования, наличие конкурентных преимуществ (климатические, географические, исторические), наличие инфраструктуры, создание условий для социализации международных студентов, формирование мультикультурной идентичности у граждан региона). 


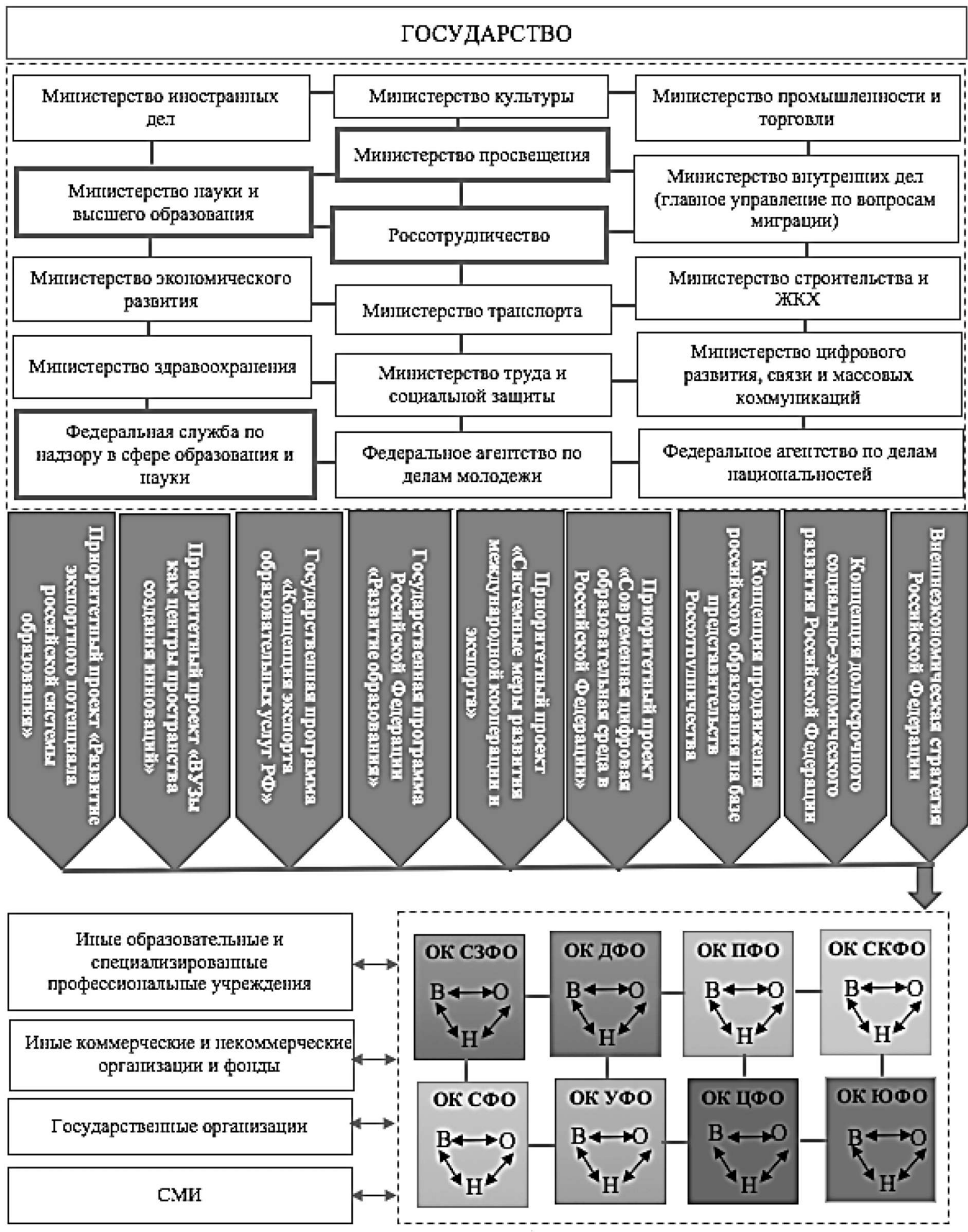

Рис. 4. Модель единого интернационального образовательного пространства на основе создания образовательных кластеров федерального значения 

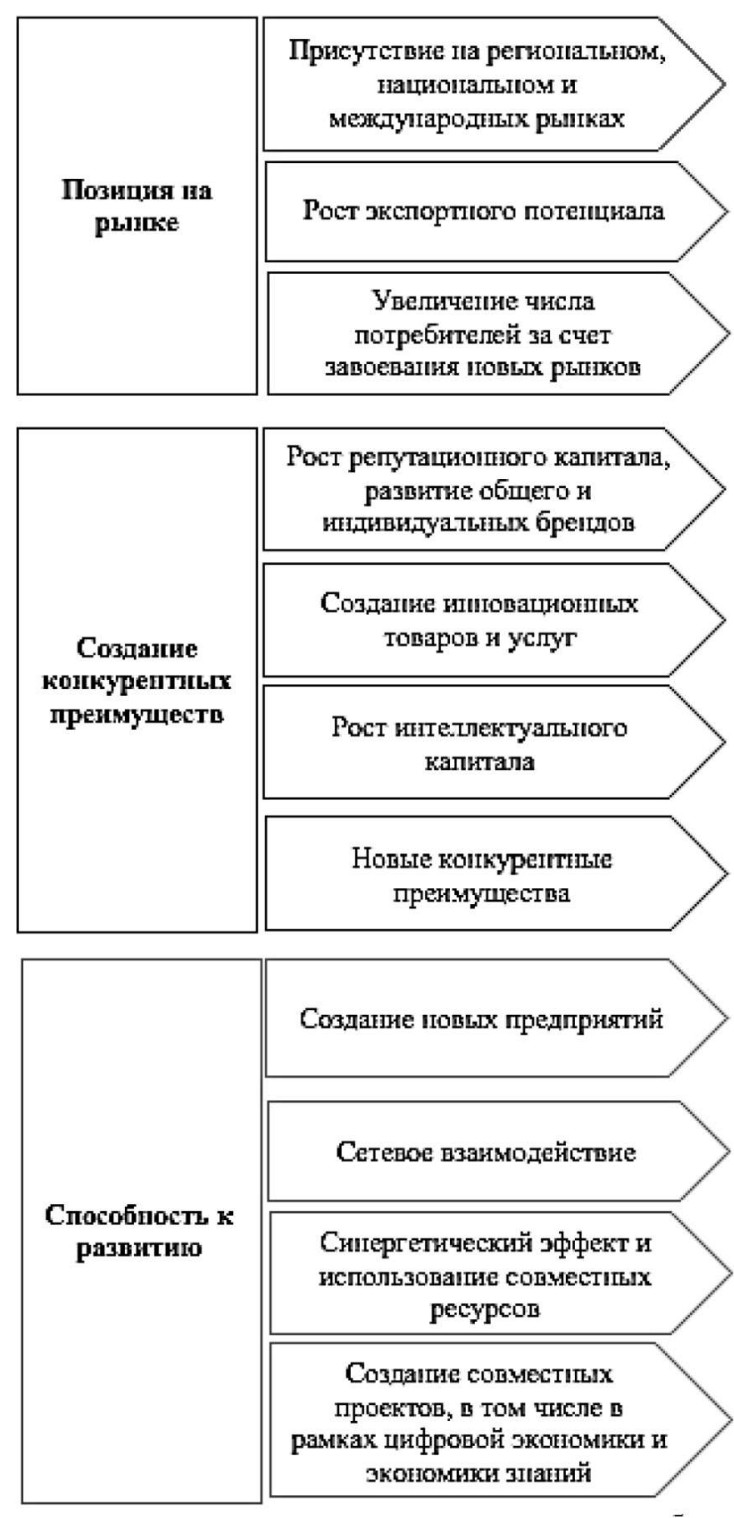

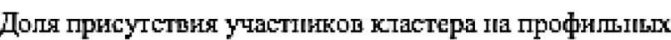
puIIKax

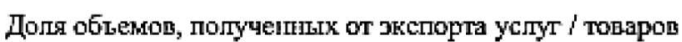

Копичесто повьх потребитетей и рыпков, па которьх присутствутот чтент кластера

Mнения экспертоп п соотетствуюшнх отрастях, места у членов кластера в профессноналышх рейтнпгах, повьшелие узианаемости

Допя новых интопационнгх товаров / услуг в общем обтеме производстта члепов ктастера

Допя высококвапифициропапньк сотрудинков участников ктастеря, нх степешь воллеченоости в ингопацин; динамика кDатификация обугающихся

Количесто колкурептних пренмушеств по сравненито с оргапизациямн, Іте входящимн в кстастер и предтаганшимн скожне товары / услуги для той же целевой аудиторин

Количество повьх инговациопных предприятий, создантьх при сопместіом участии членов кластера, а также при участии студегтов и выпускіпкков, в т.ч. междуІародыьх

Котичесто договоров завлтонених пігури кластера, а такоке с витешими оргапизациямн, в том чиспе международигыми

Эффектнпость дия кластера в целом н его чценов в частности от взаныодейстьня

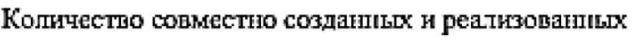
проектоп и програмы, в том чнсле с прнплечением стороникх нивестицй

Рис. 5. Критерии, показатели и способы измерения эффективности образовательного кластера

В связи с тем что образовательные кластеры предлагается создать на территории федеральных округов, за основу ядра кластера могут быть выбраны федеральные вузы, призванные стать основой для социально-экономического развития федерального округа и имеющие расширенные права и возможности при создании образовательных программ, в том числе с учетом собственных стандартов, что облегчает процедуру международной аккредитации [11]. Для остальных вузов первым критерием должно стать количество международных студентов, т. е. имеющийся опыт и потенциал для привлечения большего количества международных студентов. В случае если федеральный университет не являлся лидером по количеству международных студентов в своем федеральном округе, то помимо него выбирается вуз-лидер.

Помимо прочего выбранные вузы необходимо рассматривать через призму основных показателей конкурентоспособности, уровня международного признания, наличия связей с предприятиями, местоположения и инфраструктуры, а влияние системы высшего образования на развитие 
округа рассчитано с учетом трех субиндексов: вклад в экономическое развитие региона, вклад в развитие человеческого капитала региона, вклад в инновационное развитие региона, рассмотренных по результатам исследования «Оценка вклада региональных систем высшего образования в социально-экономическое развитие регионов России» [12]

Заключение /Conclusion. Таким образом, несмотря на то что работа по увеличению экспорта образовательных услуг в Российской Федерации ведется уже давно и своими плодами имеет разработанные программы, а именно: Государственная программа «Концепция экспорта образовательных услуг Российской Федерации на период 2011-2020 гг.», Государственная программа Российской Федерации «Развитие образования» на 2013-2020 годы; Внешнеэкономическая стратегия Российской Федерации до 2020 года; Концепция долгосрочного социально-экономического развития Российской Федерации на период до 2020 года; Концепция продвижения российского образования на базе представительств Россотрудничества; Приоритетный проект «Современная цифровая образовательная среда в Российской Федерации»; Приоритетный проект «Вузы как центры пространства создания инноваций» - больших изменений в плане экспорта образовательных услуг в Российской Федерации не наблюдалось. Одной из причин, на наш взгляд, является отсутствие единой концепции, которая бы охватывала всех участников, начиная от разработки образовательных программ и их продвижения и заканчивая специализированным законодательством, облегчающим поступление и обучение иностранных граждан в России.

При этом внедрение концептуальной модели единого интернационального образовательного пространства позволит развить имеющиеся конкурентные преимущества регионов и выбранных вузов-членов образовательного кластера, а также использовать их опыт, в том числе в международной деятельности, и имеющиеся связи с государственными, научными, образовательными и производственными структурами в совокупности с действующими государственными программами и функционированием вузов в рамках Проекта 5-100 и Приоритетного проекта «Развитие экспортного потенциала российской системы образования».

При этом уже имея преимущества российского образования для международных студентов, среди которых можно выделить: фундаментальный характер обучения, наличие развитой инфраструктуры в вузах, высокий научно-образовательный потенциал, богатый выбор вузов и специальностей, доступные цены на образование и проживание, богатое культурное, природное и историческое наследие, развитая транспортная инфраструктура и обширный выбор маршрутов для путешествий, территориальная близость с зарубежными странами, - необходимо создавать новые конкурентные преимущества в части устранения нормативно-правовых, административных, организационных и экономических барьеров.

Это позволит также повысить эффективность модели единого интернационального образовательного пространства на основе создания образовательных кластеров федерального значения и реализации иных механизмов и условий развития экспортного потенциала российской системы образования, способствующих интеграции Российской Федерации в систему мирохозяйственных связей через рост экспорта услуг высшего образования.

\section{ЛИТЕРАТУРА И ИНТЕРНЕТ-РЕСУРСЫ}

1. Сарафанова П. М. Новый подход к управлению интернационализацией высшего образования // Государственное управление. Электронный вестник. 2015. № 51. С. 104-120.

2. Marginson S., Rhoades G. Beyond National States, Markets and Systems of Higher Education: A Glonacal Agency Heuristic // Higher Education. 2002. Volume 43. Issue 3. Pp 281-309.

3. Haggins R. The Success and Failure of Policy-Implanted Iner-Firm Network Initiatives: Motivations, Processes and Structure // Entrepreneurship \&Regional Development. 2000. Volume 12. Issue 2. URL: https://www.tandfonline.com/doi/abs/10.1080/089856200283036 (дата обращения: 05.10.2018). 
4. Маковеева В. В. Сетевое взаимодействие - ключевой фактор развития интеграции образования, науки, бизнеса // Вестник Томского государственного университета. 2012. № 354. С. 163-166.

5. Богачев Ю. С., Октябрьский А. М., Рубвальтер Д. А. Механизмы развития инновационной экономики в современных условиях // ЭНСР. 2009. № 2 (45).

6. Соколова Е. И. Термин «образовательный кластер» в понятийном поле современной педагогики // Непрерывное образование: XXI век. 2014. Выпуск 2 (6). DOI: 10.15393/j5.art.2014.2371.

7. Куценко Е. Феномен образовательного кластера. URL: https://evg-ko.livejournal.com/5992.html (дата обращения: 05.10 .2018 ).

8. Porter Michael E. The Competitive Advantage of Nations // Harvard Business Review URL:http://www. economie.ens.fr/IMG/pdf/porter_1990_the_competitive_advantage_of_nations.pdf. (дата обращения: 05.10.2018).

9. Voynarenko M. Clustering within the Framework of Entrepreneurship, Economic Integration and Investment Attraction // International labour organization United Nations economic commission for Europe Regional forum «Social Aspects and Financing of Industrial Restructuring» URL: https://www.unece.org/fileadmin/ DAM/ie/wp8/documents/voynarenko.pdf (дата обращения: 05.10.2018).

10. Лапаева М. Г., Лапаев С. П. Формирование кластерной модели управления инновационными процессами в регионе // Вестник Оренбургского государственного университета. 2015. № 8 (183) С. 91-97.

11. Боровская М. А. Опыт организации сетевого взаимодействия при реализации образовательных программ федеральными университетами / М. А. Боровская, М. А. Масыч, М. В. Паничкина, Т. В. Федосова; Государственное и муниципальное управление // Ученые записки СКАГС. 2017. № 3 С. 19-25

12. Лешуков О. В. Оценка вклада региональных систем высшего образования в социально-экономическое развитие регионов России / О. В. Лешуков, Д. Г. Евсеева, А. Д. Громов, Д. П. Платонова. М.: НИУ ВШЭ. 2017. 30 c.

\section{REFERENCES AND INTERNET RESOURCES}

1. Sarafanova P. M. Novyj podhod k upravleniju internacionalizaciej vysshego obrazovanija (A new approach to managing the internationalization of higher education) // Gosudarstvennoe upravlenie. Jelektronnyj vestnik. 2015. No. 51, S. 104-120.

2. Marginson S., Rhoades G. Beyond National States, Markets and Systems of Higher Education: A Glonacal Agency Heuristic // Higher Education. 2002. No. 43. Issue 3. Pp 281-309.

3. Haggins R. The Success and Failure of Policy-Implanted Iner-Firm Network Initiatives: Motivations, Processes and Structure // Entrepreneurship \&Regional Development. 2000. No. 12. Issue 2. URL: https:// www.tandfonline.com/doi/abs/10.1080/089856200283036 (date of access: 05.10.2018).

4. Makoveeva V. V. Setevoe vzaimodejstvie - kljuchevoj faktor razvitija integracii obrazovanija, nauki, biznesa (Networking is a key factor in the development of integration of education, science and business) // Vestnik Tomskogo gosudarstvennogo universiteta. 2012. № 354. S. 163-166.

5. Bogachev Ju. S., Oktjabr'skij A. M., Rubval'ter D. A. Mehanizmy razvitija innovacionnoj jekonomiki v sovremennyh uslovijah (Mechanisms of innovative economy development in modern conditions) // JeNSR. 2009. No 2 (45).

6. Sokolova E. I. Termin «obrazovatel'nyj klasten» v ponjatijnom pole sovremennoj pedagogiki (The term «educational cluster» in the conceptual field of modern pedagogy) // Nepreryvnoe obrazovanie: XXI vek. 2014. No. 2 (6). DOI: 10.15393/j5.art.2014.2371.

7. Kucenko E. Fenomen obrazovatel'nogo klastera (The phenomenon of educational cluster). URL: https:// evg-ko.livejournal.com/5992.html (date of access: 05.10.2018).

8. Porter Michael E. The Competitive Advantage of Nations. Harvard Business Review URL: http://www. economie.ens.fr/IMG/pdf/porter_1990_the_competitive_advantage_of_nations.pdf. (date of access: 05.10.2018).

9. Voynarenko M. Clustering within the Framework of Entrepreneurship, Economic Integration and Investment Attraction // International labour organization United Nations economic commission for Europe Regional forum «Social Aspects and Financing of Industrial Restructuring» URL: https://www.unece.org/fileadmin/ DAM/ie/wp8/documents/voynarenko.pdf (date of access: 05.10.2018). 
10. Lapaeva M. G., Lapaev S. P. Formirovanie klasternoj modeli upravlenija innovacionnymi processami $\mathrm{v}$ regione (Formation of a cluster model of innovation processes management in the region) // Vestnik Orenburgskogo gosudarstvennogo universiteta. 2015. No 8 (183). S. 91-97.

11. Borovskaja M. A. Opyt organizacii setevogo vzaimodejstvija pri realizacii obrazovatel'nyh programm federal'nymi universitetami (Experience in networking in the implementation of educational programs by Federal universities) / M. A. Borovskaja, M. A. Masych, M. V. Panichkina, T. V. Fedosova; Gosudarstvennoe i municipal'noe upravlenie // Uchenye zapiski SKAGS. 2017. No. 3. S. 19-25.

12. Leshukov O. V. Ocenka vklada regional'nyh sistem vysshego obrazovanija v social'no-jekonomicheskoe razvitie regionov Rossii (Assessment of the contribution of regional higher education systems to the socioeconomic development of Russian regions) / O. V. Leshukov, D. G. Evseeva, A. D. Gromov, D. P. Platonova. M.: NIU VShJe, 2017. 30 p.

\section{СВЕДЕНИЯ ОБ АВТОРЕ}

Защитина Елена Константиновна, ассистент кафедры экономики предприятия Института управления в экономических, экологических и социальных системах Южного федерального университета. E-mail: ekzashitina@sfedu.ru

\section{INFORMATION ABOUT AUTHOR}

Zashchitina Elena, assistant professor of Enterprise economics department of Institute of Management in Economic, Environmental and Social Systems, Southern Federal University. E-mail: ekzashitina@sfedu.ru 